\title{
UMA CRONOLOGIA DO INDO-HITITA
}

\author{
GEORGE L. TRAGER
}

\begin{abstract}
Nota preliminar - $O$ artigo que aqui se traduz com a devida autorização dos seus autores foi publicado na revista norte-americana Studies in Linguistics (SIL), vol. $8, n .^{\circ} 3$, setembro de 1950. Baseia-se numa nova doutrina que surgiu no ámbito da linguística indo-européia em consequência do descobrimento do hitita e do tocariano com os seus traços muitas vêzes em desacordo com a reconstituição do indo-europeu primitivo feita anteriormente. Segundo essa nova doutrina, representada principalmente pelo linguista norte-americano Edgar Sturtevant, especialmente na sua Gramática Comparativa da Língua Hitita e em As Laringeais Indo-Hititas (de que eu fiz uma resenha no Boletim de Filologia (Rio), fasc. VI, além de uma referência na minha palestra (Os Estudos Linguísticos nos Estados Unidos da América do Norte, Avulso n. ${ }^{\circ}$ l do Museu Nacional), o hitita não é pròpriamente uma língua indo-européia no plano do indo-irânico, eslavo, itálico, helênico etc., mas uma língua cognata do indo-europeu primitivo, com êle saída de uma língua tronco anterior, convencionalmente denominada indohitita; os sons laríngeos, ou laringeais, que se depreendem no hitita, teriam existido em funcionamento ainda mais cabal neste indo-hitita, ao passo que desapareceram e são apenas deduzíveis por via indireta no indo-europeu primitivo, tal como a linguística indo-européia o reconstituiu nas obras clássicas de Brugmann, Meillet ou Hirt. É sôbre êste fundo de tela que os linguistas norte-americanos, autores dêste artigo, desenvolvem uma sugestiva e atraente teoria a respeito das migrações e fracionamentos linguisticos pertinentes à pré-história indo-européia (j. M. Câmara Jr.).
\end{abstract}

1 - O objetivo dêste artigo é apresentar em linhas gerais uma cronologia relativa e absoluta da evolução do grupo indo-hitita de línguas e indicar os marcos linguísticos principais ao longo desta marcha evolutiva, sugerindo assim atividades de pesquisa destinadas a experimentar, apurar, tornar aceitáveis ou rejeitar as hipóteses propostas.

De acôrdo com tal objetivo não daremos nenhuma bibliografia cabal nem provas elaboradas. Procuramos apoiar-nos apenas em fatos bem conhecidos e apresentá-los de uma maneira e em uma ordem tal que possa emergir, clara e convincentemente, o sistema (pattern) que êles formam. Trata-se em suma de uma exposição programática. Deseja-se debate e crítica sob todos os aspectos de detalhes e método. 
O assunto aqui incluido surgiu pràticamente sob sua forma atual do nosso trabalho no Instituto de Serviço Estrangeiro com especialistas de línguas e áreas culturais que precisavam de um background histórico para alguns de seus estudos. Verificou-se que a moderna linguística descritiva dava pontos de vista muito esclarecedores para os problemas considerados, e por êste motivo é que decidimos apresentar o assunto agora, de preferência a adiá- lo para uma elaboração mais detalhada.

A data que se adota como ponto de partida é a de 2500 a.C. Tem havido ùltimamente um razoável acôrdo geral a respeito desta data como terminus a quo da dispersão indo-européia. A fim de dar ensancha para a separação do hitita etc. acrescentamos 1000 anos, e firmamos 3500 a.C. como a data provável até quando a unidade indo-hitita se manteve inalterada. Quanto à localização territorial, há várias espécies de dados léxicos e arqueológicos, que se compadecem com as datas sugeridas e não só apontam para o Rússia meridional como a área donde partiu a dispersão, mas também indicam as linhas diretivas em que ocorreram as migrações para oeste e para o sul (1).

Depois de 3500 a.C., mas indubitàvelmente muitos séculos antes de 2500 a.C., uma parte da população falante indo-hitita começou a deixar o seu país de origem, detendo-se afinal na Anatólia e estabelecendo a família linguística anatoliana (hitita, luviano, "hitita hieroglífico", lidiano, liciano) (la.). Não há dados para se dizer se êsses povos rumaram para oeste e o sul do Mar Negro ou se atravessaram o Cáucaso para leste. A rota de oeste era

I) Cf. H. H. Bender, The home of the Indo-Europeans, Princeton, N. J. 1922; e V. Cordon Childe, The Aryans and the dawn of European civilization, New York, 1926 e 1925 resp.

la) Línguas encontradas nos reais arquivos de Boghazkoi do velho império hitita, que parece ter abrangido povos de línguas diferentes à maneira do moderno império autro-húngaro (hitita, em caracteres cuneiformes, outro hitita em caracteres hieroglificos, e luviano), e linguas encontradas alhures na Ásia Menor (lidiano, liciano) (Nota do trad.). 
certamente a mais fácil no que respeita ao terreno. As línguas que ficaram, depois da partida do anatoliano, podemos chamar o indo-europeu.

Depois da partida do anatoliano (ou possivelmente como última fase dêste movimento) desprendeu-se o grupo falante de que emergiu o armênio (2), seguindo talvez o mesmo caminho dos anatolianos; isto deve ter sucedido por volta de 2500 a.C. ou um pouco mais tarde. $O$ grupo que ficou podemos continuar a designar como indo-europeu, com a possibilidade do acréscimo de um índice numérico - $I E_{2}$. Só um pouco mais tarde partiram por sua vez os antepassados linguísticos do indo-irânico, e quase logo depois os do grupo falante helênico; dirigiram-se os primeiros para leste depois de alcançar o Mar Negro, e os segundos para oeste. Os indo-irânicos seguiram então ou rumo ao sul através do Cáucaso, ou rumo a leste para a Ásia Central e daí para o sul (com alguns, o grupo de conquistadores Mitâni, entrando na Anatólia vindos de leste) (2a.). Se foi esta a sucessão dos fatos, podemos designar a fase subsequente à partida do indo-irânico como $I_{3}$. E possivel, entretanto, que indo-irânico e helênico tenham partido por volta da mesma época.

Ao grupo linguístico mais ou menos unificado que ficou para trás, no habitat originário, podemos denominar europeu, datando- 0 de 2000 a.C. Nos 500 anos imediatamente seguintes os antepassados linguísticos do ítalo-céltico, provàvelmente de envolta com os do ilírico, messápico e (menos provàvelmente) traco-frígio - num conjunto que podemos chamar sul-e-oeste-europeu partiram numa direção geral para o sul e sudoeste. Não é impossível que o helênico se deva incluir no grupo do sul-europeu. Por

2) Cf. W. M. Austin, Is Armenian an Anatolian language?, Lang. 18. 22-5 (1942); J. A. Kerns e B. Schwartz, On the placing of Armenian, Lang. 18. 226-6 (1942).

2a) $O$ país de Mitâni, com uma língua indo-européia muito semelhante ao grupo indico, parece ter estado com o império hitita em relações análogas às velhas relações da Mongólia com a China (Nota do trad.). 
volta do fim dêste período (1500 a.C.) é que devemos colocar a partida do grupo de que resultou o tocariano.

O grupo que ficou na Rússia meridional - o dos sujeitos falantes do norte-europeu - manteve sua unidade linguistica até depois de 1000 a.C. Ai teve lugar uma separação, com a partida dos sujeitos falantes do germânico, possivelmente não todos ao mesmo tempo, entre 800 e 500 a.C. Postula-se assim que o norte-europeu comum durou de 700 a 1000 anos. Ficou o balto-eslávico depois da partida do germânico, e nos começos da era cristã o báltico rumou para o norte, deixando os eslavos como últimos ocupantes do velho território.

Convém lembrar que em muitos debates sôbre êste assunto se apresenta um diagrama especial com circulos ou ovais adjacentes, simbolizando os grupos linguisticos e interpretando a similaridade por meio da contiguidade. $O$ arranjo que aqui se apresenta é temporal, e não contradiz necessàriamente a suposição de que grupos locais diferentes tenham dado origem a migrações ulteriormente distintas. É sem dúvida razoável admitir que os caracteres que determinaram a divisão centum-satem, estavam presentes numa localização geral de oeste versus leste. Mas, nāo obstante, é importante ressaltar que as similaridades reais entre os vários grupos não podem ser explicadas apenas pela localização contígua, com a idéia subentendida de que todos os traços teriam figurado até certo ponto numa única proto-língua existente durante um dado período de tempo. Deve ter havido sucessivos movimentos migratórios e proto-línguas sucessivas.

A hipótese indo-hitita é um primeiro passo nesta direção, mas por enquanto não foi explorada a fundo (3).

Sumariando o que aqui foi exposto, apresentamos um dia-

3) Cf. E. H. Sturtevant, The Indo-Hittite Laringeals, Baltimore, 1942, passim. Ver também R. A. Hall, Jr., The reconstruction of Proto-Romance, Lang. 26.6-27 (1950), para importantes pontos metodológicos. 
grama disposto cronològicamente, sem perder de vista as localizações. (Quadro I).

\section{QUADRO 1}

3500 a. C.

Indo-hitita (IH)

2500 a. C.

Indo-europeu $\left(\mathrm{IE}_{1}\right)$

Anatoliano (An)

2300 a. C.

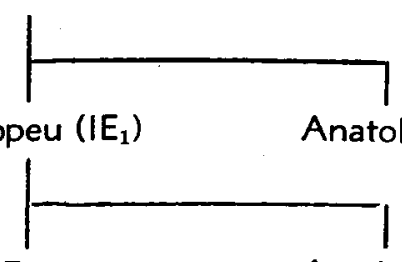

$\mathrm{IE}_{2} \quad$ Armênio (Ar)

2200 a. C.

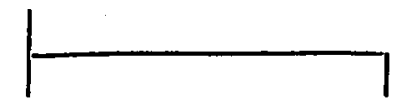

IE Indo-irânico (I-I)

2000 a. C. Helênico (He) Europeu (Eu)

1800- Sul-e-oeste (SWE) Europeu

1500 a. C. Norte Europeu (NE)

Tocariano (TC)

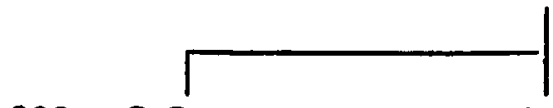

800 a. C. Germânico (Gc) Balto-eslávico (BSIc)

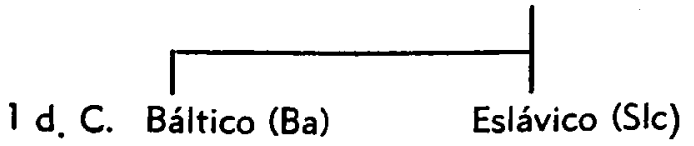

3 - Passa-se agora a apresentar as provas linguísticas. Só serão levadas em conta as partes mais indicativas das estruturas linguísticas em apreço.

IH tinha dois fonemas vocálicos - /e/, /o/, as "semivogais" /y w $\mathrm{m} \mathrm{lr} / \mathrm{e}$ pelo menos dois acentos - forte versus fraco. Se não havia distinção de acentuação, deve ter havido quatro vogais (/e o è ò/), correspondendo as duas últimas ao convencio- 
nal "xuá secundum" (3a.). Havia quatro laringeais /h, H h' H'/ (equivalentes respetivamente às de Sturtevant /'y $x$ ?/, que provàvelmente constituiam dois pares de surda-sonora (3b). As chamadas vogais longas eram vogal mais "laringeal". As "aspiradas sonoras" eram provàvelmente grupos de /b d g/ com uma ou outra laringeal (só as sonoras?). A questão das séries $k$ (3c) não precisa ser aqui apreciada, embora possamos adiantar que adotamos a solução de ter havido uma série / $\mathrm{kg} /$ e grupos destas consoantes com $/ w /$.

Pelo que se depreende do hitita, o anatoliano apresenta a redução dos quatro fonemas / $h$ H h' H'/ a uma distinção bipartida, assim:

\section{Inicial}

(') $\mathrm{h}$

(y) $\mathrm{H}$

(x) $h^{\prime}$

(?) $\mathrm{H}^{\prime}$ zero

h

h

zero

\section{Interno}

zero

h

hh

zero

Isto resultou na mudança dos alofones baixo e posterior do /e/ (3d), que existiam quando em contacto com $/ \mathrm{h} / \mathrm{e}$ $/ H^{\prime} /$, para um fonema distinto /a/. As laringeais esvaíram-se depois de oclusivas sonoras originárias ou depois de vogais finais ou pré-consonânticas.

3a) Por contingências tipográficas representamos por è, ̀̀ o que os autores do artigo representam pela vogal com uma braquia sobreposta. Xuá é um têrmo da gramática hebraica adotado pelos indo-europeistas para denominar uma espécie de vogal neutra, cuja existência no indo-europeu primitivo foi deduzida, a partir de Brugmann, pela comparaçāo do sânscrito de um lado e de outro lado o grego, o gótico e o latim (Nota do trad.).

3b) As laringeais säo sons sui-generis, assim chamados porque se lhes atribui uma natureza laringea, e que, segundo uma teoria moderna, acompanhavam as vogais $/ e /$ e $/ 0 /$, determinando mais tarde o desenvolvimento do rico vocalismo indo-europeu; cf. a Nota Preliminar (Nota do trad.).

3c) Os indo-europeistas da escola tradicional admitem a existência de duas séries de consoantes velares $(/ \mathrm{k} / \mathrm{g} /)$ e $(/ \mathrm{kw} / \mathrm{gw} /)$, em que na segunda $\circ / w /$ é um apêndice labiovelar que não tira o caráter indiviso da con-

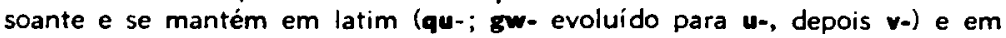
grego é responsável pela passagem da velar a labial. Os autores do artigo rejeitam, pois, o caráter indiviso das velares desta segunda série na fase inicial IH. (Nota do trad.).

3d) Na nomenclatura fonética inglêsa chama-se baixas (low) às vogais do tipo /a/, em que a lingua pràticamente não se eleva na bốca (Nota do trad.). 
Os alofones silábicos de / $\mathrm{m} \mathrm{n} \mathrm{r/} \mathrm{e} \mathrm{algumas} \mathrm{das} \mathrm{vagais} \mathrm{de}$ acento fraco também produziram casos de $/ a /$, e o / $/$ provàvelmente confluiu com o /a/. Em hitita, eventualmente, confluí$\mathrm{ram} / \mathrm{e} / \mathrm{e} / \mathrm{y} /$ silábico, de sorte que podemos descrever a situação da seguinte maneira: havia três fonemas vocálicos, /i/ e / $/$ / tinham alofones assilábicos, e assim não mais existiam $/ y /$ e $/ w /$ como fonemas distintos.

Em IE teve lugar uma fonemicização similar do /a/ com a confluência das laringeais. $\mathrm{Na}$ fase designada por $\mathrm{IE}_{1}$ é possivel ter havido dois fonemas $/ \mathrm{h} /$ e $/ \mathrm{H} /$, mas no fim do período IE é quase certo que já só havia um dêsses fonemas, $/ \mathrm{h} /$. As semivogais continuaram como já eram antes, fonemas com alofones silábicos e assilábicos. Continuaram provàvelmente tais quais os grupos de oclusiva mais laringeal. E de crer que os grupos de $/ \mathrm{kg} /$ mais $/ w /$ se tenham tornado fonemas indivisos. Depois da partida do armênio, as mudanças fonológicas nas laringeais deram em resultado o estabelecimento eventual de critérios morfológicos para um feminino em /ah/ (i.e., a longo). Nos grupos linguísticos separados - helênico, indo-irânico - realizou-se uma vocalização subsequente das semivogais silábicas, e, com a mudança do sistema de acentuação, das vogais originàriamente de acento fraco saíram várias vogais novas.

No grupo linguístico europeu, houve mudanças similares nas semivogais e vogais fracas, embora persistindo o sistema de acentuação. Os alofones silábicos de $/ \mathrm{y} / \mathrm{e} / \mathrm{w} /$ tornaram-se as vogais $/ \mathrm{i} / \mathrm{e} / \mathrm{u} /$. Os alofones silábicos de $/ \mathrm{m} \mathrm{n} / \mathrm{r} /$ tornaram-se $/ \mathrm{Vm} /$ etc. (3e), variando as vogais de acôrdo com as diferentes condições. As sequências /èh òh/ (i.e. xuá indogermanicum) passa$\mathrm{ram}$ a /ah/. Constituiram-se assim cinco fonemas vocálicos /i e a ○ u/. O sistema consonântico persistiu inalterado.

O sul-e-oeste europeu sofreu principalmente mudanças que interessaram o sistema de acentuação e o produto das laringeais, $/ \mathrm{h} /$. As sequências de $/ \mathrm{Vh} /$ (exceto /àh/) mudaram de estrutura, tornando-se vogais com acento de quantidade (fonema longo)

3e) Por $V$ entende-se qualquer vogal; a anotação $/ \mathrm{Vm} /$ corresponde assim a - vogal mais $/ \mathrm{m} /$ (Nota do trad.). 
ou possivelmente vogais geminadas, e os acentos originários parecem ter sido substituidos por um acento automático na silaba inicial de uma frase fonêmica; /àh/ tornou-se /a/. As sequências /bh/ etc. devem ter persistido por algum tempo, tornando-se eventualmente em algumas linguas (itálico) espirantes simples, e. possivelmente com uma fase intermediária espirante, em outras línguas integrando-se no quadro das oclusivas.

No norte-europeu, por outro lado, parece ter-se conservado o antigo sistema de acentuaçāo. Isto deu em resultado um sistema de três acentos nas frases, com junturas internas abertas nitidamente marcadas ( $3 f$ ). O sistema de cinco vogais reduziu-se a quatro pela confluência do $/ a /$ e do $/ 0 /$. As sequências de Nh/ ficaram paralelas a $/ V y /$ e $/ V w /$ na estrutura dos silábicos. As vogais de acento fraco ficaram sujeitas a influências analógicas ou de outra espécie, surgindo assim com qualidades inesperadas do ponto de vista histórico - por exemplo, como /i/ em vez de /a/ perto de um /y/. e assim por diante. Os grupos /bh/ etc. continuaram diferentes das oclusivas sonoras simples, possivelmente numa fase espirante (sonora).

Quando o germânico se separou do norte-europeu, caracterizou-se por mudanças em tôdas as partes do sistema fonológico. $O$ acento nos vocábulos morfològicamente indivisos foi deslocado para a sílaba inicial, mas o sistema de três acentos nas frases continuou inalterado. As junturas internas abertas eram fonèticamente muito distintas. As quatro vogais do norte-europeu reduziram-se a três pela confluência do / $i /$ e do /e/ (4). Os silábicos complexos continuaram a consistir de $/ \mathrm{V} /$ mais $/ \mathrm{h}$ y w/ (notese que h não é o símbolo do produto do "IE $k$ ", que escrevemos $/ x /$ ). As consoantes sofreram as mutações germânicas bem conhecidas.

No balto-eslávico manteve-se o sistema de três acentos, e

3f) Na nomenclatura fonèmica norte-americana, a juntura designa o comportamento de dois fonemas contiguos. Na juntura aberta o primeiro ou o segundo recebe um tratamento especial que assinala nitidamente a fronteira entre êles; a juntura interna aberta é quando há êsse tratamento sem qualquer pausa entre os dois fonemas (Nota do trad.).

4) Pretendemos debater as provas disto e suas consequências, em detalhe, num artigo subsequente. 
provàvelmente expandiu-se, de sorte que apareceram dois tipos de acentos primários, encontrando-se o novo tipo em sílabas resultantes de contrações vocálicas devidas à perda do /h/ intervocálico. As quatro vogais persistiram. / bh/ etc. confluíram com /b/ etc. Os núcleos complexos continuaram como em germânico, isto é, ficaram inalterados da fase do norte-europeu. As séries / $/ \mathrm{k}$ / de consoantes sofreram assibilação em muitas posiçōes, e $/ \mathrm{kw} /$ etc. em regra reduziu-se a $/ \mathrm{k} /$ com palatalizações ulteriores aqui e ali.

O eslávico, com a separação do báltico, reduziu as quatro vogais a duas, mediante a palatalização das consoantes diante de / i/ e /e/ e passagem a anteriores de / $u / e$ /o/ depois da consoante palatal $/ y /$ (5). A palatalização ficou fonêmicamente distinta de /y/ depois de consoante. Conservou-se a laringeal /h/. em posição inicial, tornando-se palatalizada diante de /i/ e /e/ primários, como aconteceu com as outras consoantes. Os $/ \mathrm{h} / \mathrm{,} / \mathrm{y} /$ e /w/ pós-vocálicos sofreram substituições de um pelo outro, como resultado da passagem de vogais posteriores a anteriores e de outras mudanças, mas persistiu o sistema de núcleos complexos. Continuaram os dois tipos de acentos primários, com o sistema de três acentos globais das frases inalterado. As junturas internas abertas muitas vêzes se fecharam, mas mantiveram-se como itens da estrutura total.

As evoluções fonológicas delineadas acima podem ser resumidas num Quadro II (5a). Na coluna IH figuram determinados fonemas, e os principais fonemas resultantes dos respectivos grupos linguísticos posteriores figuram ao lado em colunas apropriadas. Nas colunas $\mathrm{IH}, \mathrm{Gc}$, e Slc símbolos em itálico entre parênteses assinalam ortografias convencionais, dadas para maior clareza de referência.

4 - Para comprovação e apuração do assunto aqui exposto é necessário proceder pelo método venerando da linguística com-

5) Gordon $H$. Fairbanks num artigo por sair mostra os claros testemunhos de um sistema vocálico do tipo aqui descrito persistindo até o periodo histórico do eslávico eclesiástico num documento como o Zographensis.

5a) Por contingências tipográficas deixamos de publicar o Quadro II, assim explicado, nesta tradução (Nota do trad.). 


\title{
$-96-$
}

parativa (e muitas vêzes mais venerado do que pròpriamente respeitado). Devem ser comparadas as línguas vivas e reconstituídos os seus protótipos imediatos. Os protótipos seguintes devem ser por sua vez reconstituidos, e assim regressivamente, fase por fase. E claro que no começo deve-se ter reconstituições cabais e as várias reconstituições devem aproximar-se de uma reconstituição cabal ideal tanto quanto possivel. Só desta maneira pode-se esperar apreender coisas, que realmente tenham acontecido. na evolução das várias partes dêste bloco linguístico, que há de ser sempre, necessàriamente, um centro de interêsse para os linguistas do mundo ocidental.

25 - julho - 1950

\author{
Ceorge L. Trager \\ Henry Loe Smith, Ir. \\ (Instituto de Serviço Estrangoiro, \\ Departamento de Estado, E. U. A.).
}

